НОВЫЕ НАПРАВЛЕНИЯ В ПОЛУЧЕНИИ КАТОЛИТОВАНТИОКСИДАНТОВ МЕТОДОМ ЭЛЕКТРОАКТИВАЦИИ ВОДНЫХ РАСТВОРОВ И ИХ ИСПОЛЬЗОВАНИЕ В ПИЩЕВОЙ ПРОМЫШЛЕННОСТИ

\title{
NEW DIRECTIONS IN THE PRODUCTION OF CATHOLICS- ANTIOXIDANTS BY ELECTROACTIVATION OF AQUEOUS SOLUTIONS AND THEIR USE IN THE FOOD INDUSTRY
}

Осадченко И.М., доктор химических наук, профессор Горлов И.Ф., доктор сельскохозяйственных наук, профессор, академик РАН Андреев-Чадаев П.С., аспирант

Osadchenko I.M., doctor of chemical sciences, professor Gorlov I.F., doctor of agricultural sciences, professor, academician of RAS Andreev-Chadaev P.S., post-graduate

Поволжский научно-исследовательский институт производства и переработки мясомолочной продукции, Волгоград

Volga region research institute of manufacture and processing of meat-and-milk production, Volgograd

В статье приведены материалы о способах получения католитов путем электрообработки водных растворов солей натрия, условиях процесса, качестве католитов, в том числе антиоксидантов, по литературным данным и результатам собственных исследований, их сопоставлении и эффективности.

The article presents the materials on the methods of obtaining ka-tolites by electrical treatment of aqueous solutions of sodium salts, process conditions, the quality of Catholics, including antioxidants according to the literature and the results of their own research, their comparison and efficiency.

Ключевые слова: электрообработка, католит, антиоксидант, кислотность, окислительно-восстановительный потенциал (ОВП), качество, пищевые продукты, корма. 
Keywords: study, electrical treatment, catholyte, antioxidant, acidity, redox potential (OVP), quality, food, feed.

Развитие способов получения электроактивированных растворов католитов связано с прогрессом в различных отраслях народного хозяйства, в том числе в агропромышленном комплексе, пищевой и обрабатывающей промышленности. Важное место здесь уделяется разработке способов и технологий получения католитов-антиоксидантов.

Это связано, как мы полагаем, с особыми свойствами католитов в результате электроактивации водных растворов. При электроактивации (электрообработке) в катодной камере диафрагменного электролизера протекает ряд электродных и химических реакций. В частности, при электрообработке воды и водных растворов неорганических солей в электролизере с нерастворимыми электродами на катоде происходит разряд молекул воды с выделением водорода как в атомарной, так и в молекулярной форме. Раствор (католит) насыщается водородом, протекает процесс накопления гидроксилионов, раствор подщелачивается, происходят другие процессы с образованием активных частиц (радикалов, молекул, заряженных частиц), что приводит к понижению водородного показателя (pH) в отрицательную сторону (вплоть до -1000 мВ (ХСЭ). Протекают также процессы активации молекул воды с образованием сложных структур, некоторые из которых еще не удалось идентифицировать.

Цель работы - изучение, анализ, сопоставление условий и эффективности отечественных и зарубежных материалов по теме исследования.

Большое число публикаций свидетельствует об актуальности проблемы.

Водный раствор католита становится антиоксидантом, способным влиять на снижение содержания свободных радикалов, повышение восстановительных свойств раствора. В последние годы были проведены исследования, которые подтвердили мнение о большом влиянии антиоксидантов - катодной жидкости - на здоровье человека и животных, на ингибирование возбудителей различных заболеваний (онкозаболевания, проницаемость мембран и т.д.).

Проведенные эксперименты показали, что насыщение воды и водных растворов водородом одинаково полезно вне зависимости от формы водорода (электролитический водород, баллонный водород, химическим способом полученный водород). В некоторых публикациях появились сведения, что активный водород в католите существует в виде активной частицы с зарядом, например, $\mathrm{H}_{3}{ }^{+}$, которая образуется из $\mathrm{H}^{+}$и $\mathrm{H}_{2}$ [1]. Вероятно, эта частица го- 
раздо в большей степени растворима и стабильна в католите, чем молекулярный водород $\mathrm{H}_{2}$ (растворимость $\mathrm{H}_{2}$ в воде составляет около 2 объем.\%). Известны несколько способов получения католитов-антиоксидантов.

Известен способ раскисления молока с приданием ему физиологически активных свойств [2]. Авторы предлагают электроактивацию молока проводить на основе бездиафрагменного электролизера без применения электролита, используя собственную минерализацию молока. Электролиз осуществляли с помощью электролизера с одинаковыми плоскими графитовыми электродами до тех пор, пока кислотность молока не достигнет заданных значений в градусах Тернера. Электроактивацию проводили на бездиафрагменном электролизере с расходом молока 300 л/ч при напряжении $24 \mathrm{~B}$, силе тока 1,5 А до кислотности молока с 17,5 до $16,5^{\circ} \mathrm{T}$ и ОВП от +220 до $-350 \mathrm{MB}$, с температурой $26^{\circ} \mathrm{C}$. Полученный продукт отличался повышенной термостойкостью и высоким отрицательным потенциалом. Недостаток способа - загрязнение молока графитовым порошком.

Молоко, как известно, содержит 87\% воды, это фактически водный раствор органических компонентов молока. Авторы ссылаются на публикацию [3] о разработке по нейтрализации молока в безмембранном активаторе с алюминиевыми электродами с восстановлением исходной кислотности за счет химизма солей электролитов молока. К сожалению, сведения о других условиях ограничены.

Нами в институте проведены исследования по электрообработке прокисшего молока и молочной сыворотки в непроточном электролизере со стальным катодом и анодом ОРТА в установке «МЕЛЕСТА» в катодной камере [4]. Анолит - раствор $\mathrm{Na}_{2} \mathrm{SO}_{4}-1$ г/л. Кислотность молока (pH) снизилась с 6,4 до 7,0, окислительно-восстановительный потенциал (ОВП) имел отрицательное значение. При подобной обработке молочной сыворотки получен продукт с рН 7,0-7,8 (исходный 4,5), титруемая кислотность снизилась на $15-20^{\circ} \mathrm{T}$ (исходная $75-90^{\circ} \mathrm{T}$ ).

В заявке Японии [5] патентуется способ получения электролизом воды, содержащей растворенный водород в количестве от 0,1 до 2 частей на миллион с окислительно-восстановительным потенциалом -100 - -1000 мВ. Применяют такую воду в качестве препаратов для переливания крови, растворов для диализа, для предотвращения окисления съестных припасов в качестве добавки.

Известен способ получения антиоксиданта (католита) путем обработки жидкости в катодной камере диафрагменного электролизера до достижения католитом значения ОВП в пределах $-150--950$ мВ [6]. Католит из воды с 
$\mathrm{pH}$ 7,0 имеет значение $\mathrm{pH}$ более 7,0. Оптимальным антиоксидантом для человека является вода с рН 8, ОВП -350 мВ (ХСЭ).

Известен способ получения активированной воды путем электролиза в диафрагменном электролизере до $\mathrm{pH}$ 9,5-11,0 и последующего смешивания его с частью или всем анолитом [7]. Смесь при этом (из водопроводной воды) имела рН 7,2, ОВП -350 мВ.

Предлагается также запатентованный способ [8] получения жидкого католита-антиоксиданта, используемого в медицине, сельском хозяйстве. Обрабатываемую воду пропускали вдоль поверхности отрицательно заряженного высоковольтного электрода, варьируя значением потенциала до достижения католитом значений $\mathrm{pH}$ 7-11, после чего католит переливали в герметический сосуд, в котором создавали разрежение 5-10 Торр, сосуд заполняли до уровня 95-97\% объема, насыщали католит водородом с давлением 900-1000 Торр. К сожалению, в тексте не приведен показатель ОВП католита.

Нами впервые разработан способ получения католита-антиоксиданта в диафрагменном электролизере типа «МЕЛЕСТА» с катодом в виде пластины из алюминия и анода в виде пластины из меди (из материала ошиновки электрооборудования) площадью по 13,2 cм² с межэлектродным зазором 40 мм и выпрямителем ВСА-5К. Объем католита - 600 мл, анолита - 300 мл.

В 1-м варианте загружали питьевую водопроводную воду с $\mathrm{pH} 8,6$, ОВП +300 мВ (ХСЭ). Электрообработку проводили при силе тока 0,15 A, напряжении $36 \mathrm{~B}$, температуре $18-20^{\circ} \mathrm{C}$ в течение 40 минут. При отключении выпрямителя ВСА-5К вольтметр показывал напряжение 2 В. После обработки замеряли показатели: Д $=0,0111 \mathrm{~A} / \mathrm{cm}^{2}, \mathrm{Q}=0,111$ Амперчасов/л католита и анолита.

$\begin{array}{lll} & \mathrm{pH} & \text { ОВП, мВ (ХСЭ) } \\ \text { анолит } & 7,7 & +152 \\ \text { католит } & 9,6 & -110 .\end{array}$

Католит и анолит хранили при $+8^{\circ} \mathrm{C} 1$ сутки. После этого замеряли показатели качества (после подогрева до $20^{\circ} \mathrm{C}$ ):

$\begin{array}{lll} & \mathrm{pH} & \text { OВП, мB (ХСЭ) } \\ \text { анолит } & 7,0 & +160 \\ \text { католит } & 9,3 & -50 .\end{array}$

За 6 часов хранения при комнатной температуре (параллельно):

$\begin{array}{lll} & \mathrm{pH} & \text { ОВП, мВ (ХСЭ) } \\ \text { католит } & 9,3 & -32 .\end{array}$


Во втором варианте проводили электрообработку водного раствора 1 г/л $\mathrm{Na}_{2} \mathrm{SO}_{4}$ (600 мл католита, 300 мл анолита, как в 1-м варианте). Исходный раствор $\mathrm{Na}_{2} \mathrm{SO}_{4}-\mathrm{pH} 9,0 \mathrm{OBП}+130 \mathrm{mB}$ (ХСЭ). Опыт проводили при силе тока 0,1-0,2 A, напряжении $37 \mathrm{~B}$, температуре $18-21^{\circ} \mathrm{C}$ (обратное напряжение 2,5 В) $\mathrm{Q}=0,123$ Амперчасов/л.

Замеры показателей качества после обработки:

$\begin{array}{lll} & \mathrm{pH} & \text { ОВП, мВ (ХСЭ) } \\ \text { анолит } & 6,7 & +134 \\ \text { католит } & 11,5 & -740 .\end{array}$

В анолите обнаружено 243 мг меди (0,8 г/л). Пробы католита и анолита хранили в холодильнике. Через 50 часов:

$\begin{array}{lll} & \mathrm{pH} & \text { ОВП, мВ (ХСЭ) } \\ \text { анолит } & 7,4 & +145 \\ \text { католит } & 11,5 & -171 .\end{array}$

Порция католита в пластиковой бутылке была заморожена и хранилась в холодильной камере. Через 1 сутки:

$\begin{array}{lll}\mathrm{pH} & \mathrm{OBП,} \mathrm{мВ} \mathrm{(ХСЭ)} & \\ \text { католит } & 11,5 & -170 .\end{array}$

Через 9 суток хранения в замороженном состоянии:

$\begin{array}{lll} & \mathrm{pH} & \text { ОВП, мВ (ХСЭ) } \\ \text { католит } & 11,5 & -50 .\end{array}$

Католит-антиоксидант из раствора 1 г/л $\mathrm{Na}_{2} \mathrm{SO}_{4}$ показал хорошие результаты по качеству и хранимости: через 50 часов и 9 суток ( $\mathrm{pH}$ не изменился, ОВП в отрицательном значении -100 мВ). Наряду с католитом в процессе электрообработки образуется анолит, содержащий активную примесь сульфата меди в концентрации до 0,8 г/л. Анолит может применяться в качестве фунгицидного средства.

Впервые нами разработан способ получения католитов-антиоксидантов в электролизере с алюминиевым катодом с получением ценной продукции для пищевых целей.

Католиты электрообработанных водных растворов солей натрия применяли для обработки, замачивания семян и их прорастания с получением ростков злаков - зеленых добавок в пищевые продукты $[9,10]$. По итогам наших экспериментов можно сделать вывод, что в условиях электрообработ- 
ки с катодом из алюминия и анодом из меди образуется католит хорошего качества и хранимоспособности.

Таким образом, в результате рассмотрения способов получения католитов можно сделать заключение, что в катодной камере диафрагменного электролизера можно получать католиты, обладающие антиоксидантными свойствами с отрицательным ОВП, которые могут быть использованы для приготовления ценных и полезных веществ, в том числе добавок в пищевые продукты, обогатителей и других важных для народного хозяйства средств.

\section{Библиографический список}

1. Осадченко, И.М. Основные направления развития способов получения газообразного водорода, его свойства и применение // Альманах-2017. Волгоград: Изд. ВолГУ, 2017. - С. 135-144.

2. Пат. 2308209 РФ, А 23 L 3/32. Способ раскисления молока с приданием ему физиологически активных свойств / Болотов Н.А., Киреев Н.М., Наветный В.С., Ребров С.С. - № 2005127893; заявл. 07.09.05; опубл. 20.10.07, Бюл. № 29.

3. Бенсон, М. Электронейтрализация молока / М. Бенсон // Молочная промышленность. - 1948. - № 8. - С. 37-40.

4. Осадченко, И.М. Разработка эффективной технологии повышения качества молочной сыворотки путем снижения ее кислотности и редокспотенциала при обработке в электрическом поле электролиза / И.М. Осадченко, И.Ф. Горлов, Н.И. Мосолова, А.А. Данилеско // Аграрно-пищевые инновации. - 2018. - № 1 (1). - С. 92-94.

5. Пат. 2140881 РФ, С 02 F 1/461. Полученная электролизом вода, содержащая растворенный водород, способ получения электролизом воды и установка для получения электролизом воды / Комп. Нихон Трим Ко (JP). - № 97114611; заявл. 26.08.97, опубл. 10.11.99.

6. А. с. 1121905 СССР, С 02 F 1/46. Способ получения жидкости с биологически активными свойствами / Вахидов В.В., Мамаджанов У.Д., Касымов А.Х., Бахир В.М. [и др.]; заявл. 25.06.81.

7. А. с. 1571496 СССР, А 01 N 59/00. Способ получения стимулятора роста и развития растений / Пасько О.А. - № 4047927; заявл. 01.04.86; опубл. 30.06.90, Бюл. № 24.

8. Пат. 2456246 РФ, С 02 F 1/46. Способ получения католитаантиоксиданта и устройство для его реализации / Смирнов Г.В., Смирнов Д.Г. - № 2010116335; заявл. 23.04.10, опубл. 20.07.12, Бюл. № 20.

9. Пат. 2553238 РФ, А 01 С 1/00. Способ стимуляции проращивания семян сельскохозяйственных культур / Осадченко И.М., Горлов И.Ф., Хар- 
ченко О.В. [и др.]. - № 2013145761; заявл. 11.10.13; опубл. 10.06.15, Бюл. № 16.

10. Осадченко, И.М. Интенсивная технология проращивания семян как компонентов для пищевых целей / И.М. Осадченко, И.Ф. Горлов, Н.И. Мосолова, О.В. Харченко [и др.] // Пищевая промышленность. - 2016. - № 2. - С. 44-46. 